\title{
Radiocarbon dating wooden carvings and skeletal remains from Pitch Lake, Trinidad
}

\section{Fiona Brock ${ }^{1}$, Joanna Ostapkowicz ${ }^{2,3}$, Alex C. Wiedenhoeft ${ }^{4}$, Ian D. Bull5}

1. Cranfield Forensic Institute, Cranfield University, Defence Academy of the United Kingdom, Shrivenham, Oxon, SN6 8LA, UK.

2. World Museum, National Museums Liverpool, William Brown Street, Liverpool, L3 8EN, UK.

3. School of Archaeology, University of Oxford, 36 Beaumont Street, Oxford, OX1 2PG.

4. Center for Wood Anatomy Research, Forest Products Laboratory, One Gifford Pinchot Drive, Madison, WI, 53726, USA.

5. Organic Geochemistry Unit, School of Chemistry, University of Bristol, Cantock's Close, Bristol, BS8 1TS, UK.

Corresponding author: f.brock@cranfield.ac.uk

\section{Abstract:}

Since the mid $19^{\text {th }}$ century, rare prehistoric wooden carvings and human skeletal remains have been dredged from Pitch Lake, Trinidad, during commercial asphalt mining. Establishing a chronology for these objects is challenging, due to both a lack of stratigraphic and contextual information and the necessity to completely remove any pitch to ensure accurate radiocarbon dates. A range of solvent extraction protocols was tested to identify the most suitable one for pretreating the Pitch Lake artefacts, and then applied to ten wooden objects and a human cranium recovered from the lake. Several of these objects yielded earlier dates than expected, raising concerns that pitch had remained after pretreatment and had affected the dates. Pyrolysis-GC/MS and optical microscopy techniques were applied to material from the human cranium, a weaving tool, and a small bowl. These techniques, as well as routinely applied laboratory quality assurance procedures, indicated that there was no residual pitch within the cranium or the weaving tool after pretreatment, giving confidence to the dates. However, the small bowl was observed to still be contaminated with pitch after extensive pretreatment, indicating that the date is too old and can only be considered as a terminus post quem. 


\section{Introduction:}

Pitch Lake, at La Brea in southwest Trinidad, is a natural asphaltic lake covering nearly 100 hectares. The lake is an important economic resource for Trinidad and Tobago, having been harvested commercially since the 1850s, although documented history of its use stretches to at least the $16^{\text {th }}$ century (e.g., Whitehead 1997:131; Wiltshire 2007:12-13; Boomert 1984:23-24; Newson 1976:211) and it was likely an important resource prior to this (Boomert and Harris 1984). During the course of this commercial activity, dredging of the lake has yielded a small selection of prehistoric carved wooden artefacts as well as a number of human skeletal remains. The wooden artefacts are mostly functional domestic items such as weaving tools, bowls and paddles (compared to the more elaborate pieces recovered elsewhere in the Caribbean, e.g. Ostapkowicz et al., 2012), which could suggest they were accidentally lost or deliberately disposed of into the lake by inhabitants of lakeside ancient settlements. However, the discovery of human skeletal remains raises the potential question of whether any of the items were burial offerings intended to accompany the dead into the next world.

It is unclear how many artefacts have been dredged from the lake over the century and a half of commercial activity, but ten wooden artefacts and a human cranium are currently housed in three public collections: the National Museum \& Art Gallery of Trinidad \& Tobago, the Pointe-a-Pierre Wildfowl Trust (Peter Harris collection) in Trinidad, and the Peabody Museum of Natural History at Yale University in New Haven, USA. These pieces were studied as part of a project investigating the chronology, history and provenance of the Pitch Lake artefacts. They were radiocarbon dated to establish whether they belonged to a particular period or represented a larger timeframe of human activity around the lake - a unique resource on the island - and how they fitted into the wider corpus of prehistoric wooden carvings in the Caribbean.

However, the presence of the pitch on and potentially within the artefacts presents a significant challenge to radiocarbon dating. The pitch itself is likely to be of geological age, and hence radiocarbon-dead, and so any remaining after pretreatment will result in an erroneously old date. Therefore, should any dates be earlier than expected, it is imperative to be able to demonstrate the 
effectiveness of the pretreatment process in removing the pitch from the artefacts prior to dating. As the wooden artefacts are carved from tropical woods that do not have annual rings, dendrochronological techniques that would have avoided the issues caused by the presence of pitch could not be employed in this instance.

There appears to be a constant cycling of material within the lake, with branches of varying sizes appearing at the lake's surface before slowly sinking down again. These branches often have a thick coating of pitch, but in some instances the internal tissues appear relatively free of it. It is impossible to state from just looking at them how long these branches have been in the lake (and if they have entered the lake relatively recently from surrounding trees and grassland) and hence they may not be comparable to the prehistoric carvings that have been submerged for hundreds of years. Temperatures and pressures within the lake (which is up to $250 \mathrm{~m}$ deep) are not known, and it is not clear how wooden artefacts and bone would have been affected by the pitch over such long periods of time. One might assume that pitch, or at least lower molecular weight and/or volatile organic compounds from it, would have permeated the objects over time but in general bulk flow of pitch into wood cells would be unlikely, as the majority of the cells in wood have no openings to permit such bulk flow. Chemical species fully permeating the wood by diffusion should be below the molecular weight exclusion limit for wood (approximately 6,000 Mw: Flourney et al., 1991)

Several studies have discussed the difficulties in removing bitumen and/or tar from Egyptian mummified specimens prior to radiocarbon dating (e.g. Auferheide et al., 2004; Quiles et al., 2014). However, the success in dating both bone and plant remains from the tar pits of Rancho La Brea in California, USA (e.g. O’Keefe et al., 2009 and references therein; Fuller et al., 2014, 2015, 2016), indicated that it might be possible to produce reliable radiocarbon dates on the artefacts and skeletal remains from Pitch Lake.

Over 3 million late Pleistocene plant and animal fossils from over 600 species have been recovered from the open asphalt seeps and tar pits of Rancho La Brea (Friscia et al., 2008). More than 200 radiocarbon dates have been published on fossils from these tar pits (O'Keefe et al. 2009 and references 
therein; Fuller et al. 2014, 2015), spanning the whole radiocarbon spectrum from modern to $>50,000$ years ago. Plant specimens from the site are described as being asphalt-impregnated, and bones as having a characteristic colour from 'coffee to black' (Ho et al., 1969), indicating levels of tar contamination that penetrate further into the samples than observed in many of the Pitch Lake artefacts. All published studies of wood and bone pretreated for stable isotope analysis or radiocarbon dating from Rancho La Brea include a thorough solvent extraction protocol of some form (e.g. soxhlet extraction or ultrasonication with a range of organic solvents) to remove petroleum-based contamination (e.g. Ho et al., 1969; Coltrain et al., 2004; Fox-Dobbs et al., 2006; Friscia et al., 2008; O’Keefe et al., 2009; Fuller et al., 2014; 2015). However, several of these (e.g. Ho et al., 1969; Coltrain et al., 2004; Fuller et al., 2014, 2015) suggest that the solvent extraction itself is insufficient to remove the tar from the Rancho La Brea samples, with insoluble aggregates, residues and colloidal asphaltenes thought to be remaining (Fuller et al., 2014). Consequently, bone specimens in particular, have subsequently undergone further rigorous pretreatments prior to dating, including liquid chromatography extractions (Ho et al., 1969), amino acid analysis (Stafford et al., 1991), and a double ultrafiltration procedure (Fuller et al., 2014; 2015).

However, the asphalt from Pitch Lake is unlikely to be chemically identical to that from Rancho La Brea, and the conditions within the lake will differ from those of the tar pits. Hence, it cannot be assumed that a radiocarbon pretreatment protocol that is effective at one site will also be the most suitable pretreatment at the other. This paper details the comprehensive experimental work undertaken to test a range of published solvent extraction protocols to identify and then apply the most suitable one for removing Pitch Lake contamination from human remains and wooden artefacts.

The project is constrained by the fact that particular care needs to be taken with objects of cultural patrimony held in museum collections, where conservation as well as aesthetic issues severely limit sampling sizes. This limited the opportunity for multiple dates on individual artefacts using different radiocarbon protocols that could have provided additional confidence in the dating. Given the lack of stratigraphy or contextual information for the pieces 
from the lake, it was vital to be able to demonstrate the effective removal of pitch from the pieces to provide confidence in the dates, especially those objects with the earliest dates. However, this is particularly difficult for the wooden artefacts, as a large component of pitch is degraded organic plant matter, and so chemically indistinct from the sample material. Hence techniques sometimes applied for the quality assurance of radiocarbon dates on wood, such as comparison of $\delta^{13} \mathrm{C}$ stable isotopic values and FTIR are not applicable in this instance. Instead, optical microscopy techniques and pyrolysis-GC/MS, which are less commonly applied in radiocarbon dating, were used to look for visual signs of residual pitch and the presence of compounds indicative of pitch contamination, respectively. The efficiency of pitch removal from three of the artefacts that yielded the earliest dates from the corpus - the human cranium, a weaving tool, and a small bowl - is assessed here.

Detailed descriptions of the ten Pitch Lake wooden artefacts and the human cranium, the sampling strategies involved, the radiocarbon dates and their interpretation will be published separately by Ostapkowicz et al. (submitted).

\section{Methods:}

\subsection{Pitch decontamination:}

\subsubsection{Initial dissolution experiments}

Initial tests were undertaken to visually assess the impact of different organic solvents on crust material recently collected from the surface of Pitch Lake. Aliquots of crushed pitch crust were treated three times for 15 min each with ultrasonication with fresh aliquots of the following solvents: acetone, hexane, dichloromethane, petroleum ether, chloroform, toluene. Each solvent was chosen as it is ultilised in at least one published method for bitumen or asphalt removal prior to radiocarbon dating specimens from Rancho La Brea or mummified Egyptian artefacts (e.g. Aufderheide et al., 2014; Ho et al., 1969; O’Keefe et al., 2009; Quiles et al., 2014; Fuller et al., 2014). The colour released on each wash and a visual estimation of the amount of pitch dissolved was noted. 
Recently collected pitch from the surface crust of Pitch Lake was ground using a pestle and mortar and mixed in a 1:4 ratio with Chromosorb, a carbon-free silica substrate used in previous 'contamination-removal' experiments (Dee et al. 2011) and placed in 2 separate glass vials. The Chromosorb and pitch was mixed thoroughly by vortexing before placing each vial in separate wide-necked conical flasks, each containing two open glass vials of water. The flasks were sealed with rubber bungs held in place with wire and kept at $60^{\circ} \mathrm{C}$ for 1 month to artificially age the pitch onto the Chromosorb. While no viscous pitch was available for this experiment (due to concerns about transporting flammable material from Trinidad to the UK), Chromosorb is much more absorbant than wood or bone, and the crust will not bond to Chromosorb as it would with wood or bone within Pitch Lake, experiments such as these allow for the removal of pitch to be assessed relatively quickly and cheaply, by applying different solvent extraction protocols and measuring the remaining carbon present on the Chromosorb by mass spectrometry. Once the most effective pretreatment for removing the pitch from the Chromosorb was identified, it could be tested by deliberately contaminating known-age wood with pitch and dating the pretreated material.

Nine different solvent extraction protocols were applied in triplicate to $c a$. $10 \mathrm{mg}$ aliquots of pitch-contaminated Chromosorb as described below. Note: in the following, Pet. Ether = petroleum ether; Ace. = acetone; Hex. = hexane; Chlor. = chloroform; Meth. = methanol; Tol. = toluene; $\mathrm{DCM}=$ dichloromethane; $\mathrm{MQ}=$ ultrapure Milli-Q water; $\mathrm{u} / \mathrm{s}=$ ultrasonication.

A: Pet ether, ace., hex. sequence consisting of $5 \times 5$ min washes with fresh solvent and $\mathrm{u} / \mathrm{s}$ followed by 2 hours soaking per solvent before progressing to the next solvent. (O'Keefe et al., 2009).

B: Ace. $\left(1\right.$ hour, $\left.45^{\circ} \mathrm{C}\right)$, meth. $\left(1\right.$ hour, $\left.45^{\circ} \mathrm{C}\right)$, chlor. $(1$ hour, room temperature). This is the routine solvent extraction applied to samples at the Oxford Radiocarbon Accelerator Lab (ORAU) (Brock et al., 2010).

C: 2 x hex. (15 min); 2 x DCM (15 min); 2 x chlor. (15 min), all with u/s (Quiles et al., 2014)

D: $2 \times$ tol. (30 min, u/s); $2 \times 2: 1$ tol: meth (30 min, u/s); $2: 1$ tol:meth (30 min, $\mathrm{u} / \mathrm{s}$, then left to soak overnight for a minimum of 17 hours); $2: 1$ tol: meth (30 
min, u/s); 2 x meth (30 min, u/s); 2 x MQ (30 min, ultrasonication). Based on Fuller et al. (2014).

E: 4 x 2:1 tol: meth (30 min, u/s), 2:1 tol:meth (30 min, u/s, then left overnight for min 17 hours), 2:1 tol: meth (30 min, u/s), 2 x meth (30 min, u/s), $2 \times$ MQ (30 min, u/s). Adapted from Fuller et al. (2014).

F: 2 x DCM (30 min, u/s); 2 x 2:1 DCM: meth (30 min, u/s); 2:1 DCM:meth (30 $\min , \mathrm{u} / \mathrm{s}$, then left to soak overnight for a minimum of 17 hours); 2:1 DCM: meth (30 min, u/s); $2 \times$ meth (30 min, u/s); $2 \times$ MQ (30 min, u/s).

G: 4 x 2:1 DCM: meth (30 min, u/s), 2:1 DCM:meth (30 min, u/s, then left overnight for min 17 hours), 2:1 DCM: meth (30 min, u/s), 2 x meth (30 min, u/s), $2 \times$ MQ (30 min, u/s).

$\mathrm{H}: 2 \times$ chlor. $(30 \mathrm{~min}, \mathrm{u} / \mathrm{s}) ; 2 \times 2: 1$ chlor.: meth $(30 \mathrm{~min}, \mathrm{u} / \mathrm{s}) ; 2: 1$ chlor:meth (30 min, $\mathrm{u} / \mathrm{s}$, then left to soak overnight for a minimum of 17 hours); 2:1 chlor: meth (30 min, u/s); 2 x chlor. (30 min, u/s); $2 \times$ MQ (30 min, u/s).

I: 4 x 2:1 chlor: meth. $(30 \mathrm{~min}, \mathrm{u} / \mathrm{s}), 2: 1$ chlor:meth $(30 \mathrm{~min}, \mathrm{u} / \mathrm{s}$, then left overnight for min 17 hours), 2:1 chlor.: meth. (30 $\mathrm{min}, \mathrm{u} / \mathrm{s}), 2 \mathrm{x}$ meth. $(30 \mathrm{~min}$, u/s), $2 \times$ MQ (30 min, u/s).

The final products were air-dried before the remaining Chromosorb was analysed for carbon content using mass spectrometry as described by Dee et al. (2011). The levels of carbon present on uncontaminated Chromosorb and Chromosorb contaminated with pitch were also measured.

\subsection{3 (De-)Contamination of known-age wood}

Several small (ca. 5 × 5 × $10 \mathrm{~mm}$ ) pieces of known-age Irish bog oak, dendrochronologically dated to AD 1481-1490 (Brock et al. 2010) were taken to Trinidad, and stored in fresh viscous pitch collected from Pitch Lake for 3 days. The samples then underwent the most effective solvent extraction sequence for removing Pitch Lake crust material from Chromosorb (method E, above) prior to dating by both $\alpha$-cellulose extraction and the routine ABA-bleach method for wood samples at ORAU (see below) to ensure that accurate dates for the wood could be achieved. 


\subsection{Radiocarbon dating}

Detailed descriptions of the complete corpus of wooden artefacts and skeletal remains from Pitch Lake studied in this project, and the sampling strategy applied, will be provided by Ostapkowicz et al. (submitted). However, the work presented here focused on 3 pieces in particular:

- A human cranium mounted in pitch (National Museum and Art Gallery of Trinidad and Tobago)

- A small wooden bowl (National Museum and Art Gallery of Trinidad and Tobago

- A weaving tool without handle (hence forth 'weaving tool') (Harris Collection/Pointe-a-Pierre Wildfowl Trust, Trinidad)

Areas of the artefacts heavily contaminated with pitch were avoided during sampling where possible. Wooden objects were sampled from the outermost rings to represent the time when the tree was felled and most likely carved. Sampling locations also needed to be sympathetic to the carvings and cranium, without causing visual damage in key areas of interest. Therefore, for many of the ten wooden artefacts dated from Pitch Lake, the amount of material available for dating was limited, ranging from 14 to $105 \mathrm{mg}$, with most being ca. $30 \mathrm{mg}$. For the 2 pieces discussed here, $78 \mathrm{mg}$ was sampled from the small wooden bowl and $52 \mathrm{mg}$ from the weaving tool. The pretreatment protocols applied to each are described below. All solutions and water washes were carried out with ultrapure MilliQ ${ }^{\mathrm{TM}}$ water, and all solvents used were Distol grade. Following pretreatment, samples were freeze-dried before being combusted and the resultant $\mathrm{CO}_{2}$ cryogenically distilled, graphitised and AMS radiocarbon dated as described by Brock et al. (2010).

\subsubsection{Solvent removal}

All samples underwent solvent extraction method E, as described above. Care was taken in particular to ensure that the bone powder from the human cranium was not heated unnecessarily during ultrasonication to avoid damaging the collagen present.

\subsubsection{Radiocarbon dating pitch}


Two aliquots of pitch were directly dated with no pretreatment. One sample was collected from the surface of a ceremonial bench previously dated by Ostapkowicz et al. (2012). A second sample of crust collected from the surface of Pitch Lake in 2014 was also dated.

\subsubsection{Bone pretreatment}

Bone powder (145 mg) was sampled from the human cranium, taking care to avoid any obvious regions of pitch. Following solvent extraction as described above, the sample underwent a modified Longin (1971) extraction procedure consisting of an acid-base-acid (ABA) wash $(0.5 \mathrm{M} \mathrm{HCl}, 3-4$ times over $\sim 18$ hours; $0.1 \mathrm{M} \mathrm{NaOH}, 30 \mathrm{~min} ; 0.5 \mathrm{M} \mathrm{HCl}, 1$ hour, all at room temperature and with thorough rinsing with ultrapure water in between each step) followed by gelatinization at $\mathrm{pH} 3$ and $75^{\circ} \mathrm{C}$ for 20 hour. The resultant solution was then filtered using a cleaned 45-90 $\mu \mathrm{m}$ Ezee-filter ${ }^{\mathrm{TM}}$ (Elkay, UK; Brock et al., 2010) prior to freeze-drying. To demonstrate that the final date of the cranium was not affected by laboratory-introduced contamination, especially from the extensive solvent pretreatment, or influenced by the small size of the sample, a similarsized aliquot (210 mg) of a known-age in-house laboratory bone standard (a pigrib from the wreck of the Mary Rose, dating to ca. AD 1545 AD) was treated alongside the cranium sample.

\subsubsection{Wood pretreatment}

Two separate pieces of the known-age wood that had been contaminated with pitch were each dated twice, using $\alpha$-cellulose extraction and acid-baseacid(ABA)-bleach protocols, as described below. The $\alpha$-cellulose method is more rigorous, but the harsh conditions require a high starting weight (min. $50 \mathrm{mg}$ ) that was not available for most of the samples due to the difficulties in sampling described above. Therefore, only the ABA-bleach method could be applied to most of the samples in this study, including the small bowl and weaving tool detailed here.

The $\alpha$-cellulose method (described in detail by Staff et al., 2014), is as follows: $4 \%(1.12 \mathrm{M}) \mathrm{HCl}\left(70^{\circ} \mathrm{C}, 20 \mathrm{~min}\right) ; 17.5 \% \mathrm{w} / \mathrm{v} \mathrm{NaOH}$ (1 hour, room temperature, ultrasonication under constant nitrogen atmosphere); 5\% (1.4M) 
$\mathrm{HCl}\left(70^{\circ} \mathrm{C}, 10 \mathrm{~min}\right)$, with thorough rinsing with ultrapure water after each stage (3-6 washes).

The routine ABA-bleach wood method is described by Brock et al. (2010; lab code UW) as follows: $1 \mathrm{M} \mathrm{HCl}\left(80^{\circ} \mathrm{C}, 20 \mathrm{~min}\right) ; 0.2 \mathrm{M} \mathrm{NaOH}\left(80^{\circ} \mathrm{C}, 20 \mathrm{~min}\right) ; 1 \mathrm{M}$ $\mathrm{HCl}\left(80^{\circ} \mathrm{C}, 1\right.$ hour); $5.0 \%$ (w/v) $\mathrm{NaClO}_{2}$ bleach $\left(\mathrm{pH} 3,80^{\circ} \mathrm{C}\right.$, up to $\left.30 \mathrm{~min}\right)$, with thorough rinsing with ultrapure water between each step.

\subsection{Pyrolysis-GC/MS}

Untreated material from the human cranium and weaving tool, as well as pretreated material from the weaving tool were analysed using Py-GC/MS at the NERC LSMSF facility at the University of Bristol, UK. Py-GC/MS was performed using a Chemical Data Systems (CDS) 5200 series pyroprobe pyrolysis unit attached to an Agilent 6890A gas chromatograph (GC) fitted with an CPSil-5CB fused column (Varian 100\% dimethylpolysiloxane; 50m, 0.32mmi.d.; $0.45 \mu \mathrm{mfilm}$ thickness) and a ThermoElectron MAT95 double focussing mass spectrometer (ThermoElectron, Bremen) operated in electron ionization (EI) mode (EI source temperature $200^{\circ} \mathrm{C}$, interface $\left.310^{\circ} \mathrm{C}\right)$ with helium as a carrier gas $(2 \mathrm{~mL} / \mathrm{min})$. Samples were pyrolysed in a quartz tube at $610^{\circ} \mathrm{C}$ for $20 \mathrm{~s}$, transferred to the GC using a pyrolysis transfer line $\left(310^{\circ} \mathrm{C}\right)$ and injected onto the GC using a split ratio of $10: 1$; the injector port temperature was maintained at $310^{\circ} \mathrm{C}$. The oven was programmed to heat at $4^{\circ} \mathrm{C} / \mathrm{min}$ from $50^{\circ} \mathrm{C}$ (held for $4 \mathrm{~min}$ ) to $300^{\circ} \mathrm{C}$ (held for 15 min). The MS scanned the range $m / z 50-650$ at a rate of one scan per second and there was a solvent delay of 7 min. Data was collected using MAT95InstCtrl v1.3.2 and viewed using QualBrowser v1.3 (ThermoFinnigan, Bremen). Compounds were identified using the National Institute of Standards and Technology (NIST) database.

\subsection{Optical microscopy.}

Treated wood specimens were placed on labelled microscope slides. A drop of 1:1 glycerine:95\% ethanol was added to each sample, with a coverslip placed atop this. The slides were heated on a hot plate at $c a .120^{\circ} \mathrm{C}$ until air bubbles stopped exiting the wood material. The camera was white balanced against the 
glycerine mounting medium for each slide and each magnification prior to images being recorded. Exposure times for the digital camera (Point Grey Flea 3 Model FL3-U3-88S2C-C) were manually adjusted to maximize the dynamic range of the sensor ("white" areas without tissue with RGB intensity peaks between 220 and 255).

\section{Results and discussion:}

\subsection{Pitch decontamination}

Initial visual tests demonstrated that chloroform and toluene were the two most successful individual organic solvents at dissolving pitch, followed by dichloromethane. The chloroform had dissolved the majority of the pitch after the first 15 min wash with ultrasonication. A much slower response was observed with petroleum ether, the second wash resulting in some loss of sample. Hexane and acetone appeared to have very little effect on the pitch. This is generally as expected, as Attwooll and Broome (1954) reported the solubility of viscous pitch from Pitch Lake as highest in chloroform (53\%) and toluene (50\%) and lowest in petroleum ether (35\%) and acetone (26\%). Ho et al. (1969) also reported that extensive soxhlet extraction of asphalt-impregnated samples from Rancho La Brea with petroleum ether was unsuccessful, while Fuller et al. (2014) predicted the success of toluene in removing Rancho La Brea tar given its affinity for aromatic compounds.

The results of the different solvent extraction protocols are given in Table 1.

\begin{tabular}{|l|l|l|}
\hline Solvent pretreatment method & $\begin{array}{l}\text { Average } \\
\text { \%wt C } \\
\text { remaining } \\
(\mathrm{n}=3)\end{array}$ & $\begin{array}{l}\text { \%wt C } \\
\text { Standard } \\
\text { deviation }\end{array}$ \\
\hline Uncontaminated Chromosorb & $0.01^{*}$ & 0 \\
\hline Contaminated Chromosorb & $9.94^{*}$ & 4.81 \\
\hline A: petroleum ether/acetone/hexane & 4.05 & 1.69 \\
\hline B: acetone/methanol/chloroform & 1.21 & 0.58 \\
\hline C: hexane/dichloromethane/chloroform & 0.07 & 0.02 \\
\hline
\end{tabular}




\begin{tabular}{|l|c|l|}
\hline D: toluene/toluene:methanol/methanol/water & 0.10 & 0.02 \\
\hline E: toluene:methanol/methanol/water & 0.07 & 0.01 \\
\hline F: DCM/DCM:methanol/methanol/water & 0.12 & 0.05 \\
\hline G: DCM:methanol/methanol/water & 0.87 & 0.80 \\
\hline $\begin{array}{l}\text { H: } \\
\text { chloroform/chloroform:methanol/methanol/water }\end{array}$ & 0.23 & 0.07 \\
\hline \begin{tabular}{l} 
I: chloroform:methanol/methanol/water \\
\hline
\end{tabular} & 1.21 & 0.70 \\
\hline
\end{tabular}

Table 1: Average percentage of carbon within the pitch-contaminated

Chromosorb after each solvent extraction procedure. $\left({ }^{*} n=4\right)$

Analysis of the uncontaminated Chromosorb confirms that only trace levels of carbon are present, and any carbon on the contaminated Chromosorb is present as pitch. Presence of pitch on the contaminated stock Chromosorb is clearly variable, no doubt due to the difficulty of producing an entirely homogeneous mix of pitch and Chromosorb.

The effectiveness of the different solvent sequences at dissolving pitch will depend on the polarity of both the solvents used and the components of the pitch itself. A non-polar solvent is required initially to dissolve the many hydrocarbons within the pitch; use of a solvent that is too polar for the initial treatment may inhibit the solubility of polar components in subsequent treatments with more polar solvents. Comparison of the 'paired' solvent treatments (e.g. D vs E, F vs G, H vs I) suggests that the binary mixes of DCM:methanol and chloroform:methanol are not sufficiently non-polar to dissolve the large nonpolar component of the pitch, and hence remove less of the pitch from the Chromosorb than the same treatments preceded with an initial DCM or chloroform wash. However, toluene is less polar than both DCM and chloroform, and it appears that the toluene:methanol mixture (method E) was as effective at removing the pitch as method $\mathrm{F}$ which started with an initial toluene-only wash.

Of the nine methods tested, the most successful at removing the pitch from the Chromosorb were the toluene and methanol-based procedure based on that of Fuller et al. (2014) and the hexane/dichloromethane/chloroform sequence proposed for removal of bitumen from Ancient Egyptian samples by Quiles et al. 
(2014), with just $0.07 \%$ residual carbon from both. It was decided to apply the toluene and methanol-based procedure (method E) to the Pitch Lake samples because of the success of dating the Rancho La Brea samples by Fuller et al. $(2014,2015)$ using this protocol, and also because Quiles et al. (2014) highlighted that their method, while effective at removing modern bitumen, was less effective at removing it once it was aged.

In some of the decontaminated Chromosorb, small black specks of solid material could be observed against the white of the Chromosorb, highlighting the presence of insoluble residues. However, these were very clear to the naked eye, and it was anticipated that they could be removed from pretreated collagen or wood manually prior to combustion if necessary.

The least successful method for removing the pitch was that based on the petroleum ether/acetone/hexane method used by O'Keefe et al. (2009) for pretreating specimens from Rancho La Brea, with an average of $4.05 \%$ carbon remaining on the Chromosorb after treatment. However, Fuller et al. (2015) previously identified that the dates generated by O'Keefe et al. (2009) may have been slightly older than the true date, and that the original pretreatment applied was insufficient to remove all remaining tar. It should also be stressed that as the asphalt from the two sites is likely to be chemically different, it should not be assumed that the same solvent sequence will remove the contaminant from material from both sites.

Two pieces of known-age wood that had been contaminated with pitch were each solvent extracted using the toluene/methanol sequence (method E) before being dated twice, once following $\alpha$-cellulose extraction and once using an acid-base-acid-bleach protocol. The $\alpha$-cellulose dates were $369 \pm 23 \mathrm{BP}$ and 368 $\pm 23 \mathrm{BP}$, and the ABA-bleach dates were $378 \pm 22 \mathrm{BP}$ and $374 \pm 26 \mathrm{BP}$. All four dates were within the expected range given the known age of the material (AD 1481-1490). While this experiment could not replicate removal of pitch from wood that had been submerged in it for hundreds of years, it did provide some confidence in applying the ABA-bleach method to those samples for which there was insufficient material (i.e. $<50 \mathrm{mg}$ ) for the more rigorous $\alpha$-cellulose method.

\subsection{Radiocarbon dating}


The results of the radiocarbon dating of the pitch, the human cranium, and the two wooden artefacts (the bowl and the weaving tool), are presented in Table 2. (see Ostapkowicz et al. submitted, for further discussion).

\begin{tabular}{|l|l|l|l|l|l|l|}
\hline Sample & $\begin{array}{l}\text { Pretreat } \\
\text { ment } \\
\text { yield (\%) }\end{array}$ & $\begin{array}{l}\delta^{13} \mathrm{C} \\
(\% 0)\end{array}$ & $\% \mathrm{C}$ & $\begin{array}{l}\mathrm{C}: \mathrm{N} \\
\text { ratio }\end{array}$ & $\begin{array}{l}\text { 14C Date } \\
\text { BP } \\
\text { Uncal. }\end{array}$ & OxA \\
\hline $\begin{array}{l}\text { Pitch ( } \\
\text { bench } \\
\text { surface) }\end{array}$ & $100 \%$ & -27.8 & 47.7 & $\mathrm{n} / \mathrm{a}$ & $\begin{array}{l}41300 \pm \\
800\end{array}$ & X-2391-7 \\
\hline $\begin{array}{l}\text { Pitch lake } \\
\text { crust }\end{array}$ & $100 \%$ & -28.4 & 48.5 & n/a & $\begin{array}{l}44400 \pm \\
130\end{array}$ & 30480 \\
\hline Cranium & $1.8 \%$ & -18.2 & 41.7 & 3.2 & $2222 \pm 27$ & X-2590-53 \\
\hline $\begin{array}{l}\text { Small } \\
\text { bowl }\end{array}$ & $31.3 \%$ & -24.1 & 43.1 & n/a & $4106 \pm 30$ & 31970 \\
\hline $\begin{array}{l}\text { Weaving } \\
\text { tool }\end{array}$ & $37.3 \%$ & -24.6 & 40.7 & n/a & $4472 \pm 32$ & 31972 \\
\hline
\end{tabular}

Table 2. Radiocarbon results for the pitch, the human cranium, and 2 wooden artefacts. The percentage yield, $\delta^{13} \mathrm{C}$ value, and $\%$ carbon content on combustion of all samples are recorded, as well as the C:N ratio of the cranium.

\subsubsection{Pitch radiocarbon dates.}

The 2 uncalibrated radiocarbon dates on the different samples of pitch both gave similar results close to background radiocarbon levels, of $41300 \pm 800$ $\mathrm{BP}$ and $44400 \pm 1300 \mathrm{BP}$ (Table 2). These dates are in agreement with dates for Rancho La Brea tar, as recorded by Fuller et al. (2014). The asphalt from both sites is expected to be geological in origin and therefore beyond the range of radiocarbon, but the dates likely reflect the input of modern carbon from plant material and sediment into the lake and tar pits.

\subsubsection{Radiocarbon date of the human cranium}


The sample of bone from the human cranium yielded 1.8\% wt collagen, which dated to $2222 \pm 27 \mathrm{BP}$. The collagen was fluffy with a very pale golden colour, in contrast to some of the contaminated collagen from Rancho La Brea, which was described as 'tan' and 'very dark brown to black' by Fuller et al. (2014). Several small black specks, presumably of insoluble pitch, were clearly visible within the freeze-dried collagen but were easily removed by hand prior to combustion and dating. The C:N ratio of the collagen was 3.2, within the acceptable range of 2.9-3.5 (Ambrose, 1990), and the range of 3.2-3.5 suggested by Fuller et al. (2015) for bones from Rancho La Brea. The \%C content of 41.7\% was consistent with recorded values for collagen (Ambrose, 1990). Neither the $\mathrm{C}: \mathrm{N}$ ratio and \%C suggested the presence of additional carbon which would have been expected with residual pitch.

The known-age bone standard that was treated and dated alongside the cranium to assess for any contamination introduced during pretreatment (especially the extensive solvent extraction sequence) produced a date in line with expected values (Brock et al. 2007), indicating that the pretreatment process itself had not added any old carbon to the sample.

The sample was not ultrafiltered (either to collect the $>30 \mathrm{kDa}$ fraction as routine at ORAU (Brock et al., 2010) or the $>3 \mathrm{kDa}$ and $<30 \mathrm{kDa}$ fractions outlined by Fuller et al. (2015) for tar-steeped samples) primarily because ultrafiltration tends to result in a reduced sample yield. As the sample was already small (145 mg starting weight) any unnecessary loss of collagen was to be avoided where possible.

The original plan was also to use single amino acid dating on the cranium to verify the date, but there was insufficient material to do this. However, the combination of the pale golden colour of the collagen, the $\% \mathrm{C}$ content and C:N ratio of the collagen, and the date of the associated known-age standard, all indicate that the collagen extracted from the cranium sample was not contaminated with pitch and that the date of $2222 \pm 27 \mathrm{BP}$ is accurate.

\subsubsection{Radiocarbon dating of wooden artefacts}

Both the small bowl and the weaving tool yielded pretreated material that gave no indication by colour of any residual pitch contamination. A few small 
specks of black insoluble residue were visible in both samples, as for the cranium, but were easily removed manually prior to dating. Both objects gave much older radiocarbon dates than expected of $4106 \pm 30 \mathrm{BP}$ and $4472 \pm 32 \mathrm{BP}$ respectively. There was not sufficient material available to redate either piece from scratch to confirm these dates, but there was sufficient pretreated material remaining from the weaving tool to combust and date again. The second date, however, was identical to the first (4472 $\pm 32 \mathrm{BP}$ ), indicating that there had been no residual insoluble pitch in the first sample dated: it is highly unlikely that exactly identical amounts of contamination would have been present in both fractions to result in the same dates, and hence a contaminated sample would have been expected to yield two different dates.

Pretreated material from both the small bowl and the weaving tool therefore required further analysis to be able to demonstrate with confidence whether or not any pitch remained in the wood after pretreatment that could have resulted in older dates than expected.

It should be noted that two dates on a sample taken from a different location on the small bowl were also much older than expected (4197 $\pm 32 \mathrm{BP}$ (OxA-31395) and $4273 \pm 29$ BP (OxA-31496); Ostapkowicz et al., submitted) but no untreated or treated material remained for further investigation.

\subsection{Pyrolysis-GC/MS}

Py-GC/MS is a highly sensitive technique, and has been used to characterise geological and petrochemical samples, including the use of asphalt in historical artwork (Languri et al. 2002). The technique was used to look for specific markers in the pretreated sample material that would have been present in pitch but not in plant wood, in particular the presence of alkene/alkane doublets typical of asphaltenes and hopanes (m/z 191). Attwooll and Broome (1954) state that 33\% of total soluble bitumen from Pitch Lake is comprised of asphaltenes. 


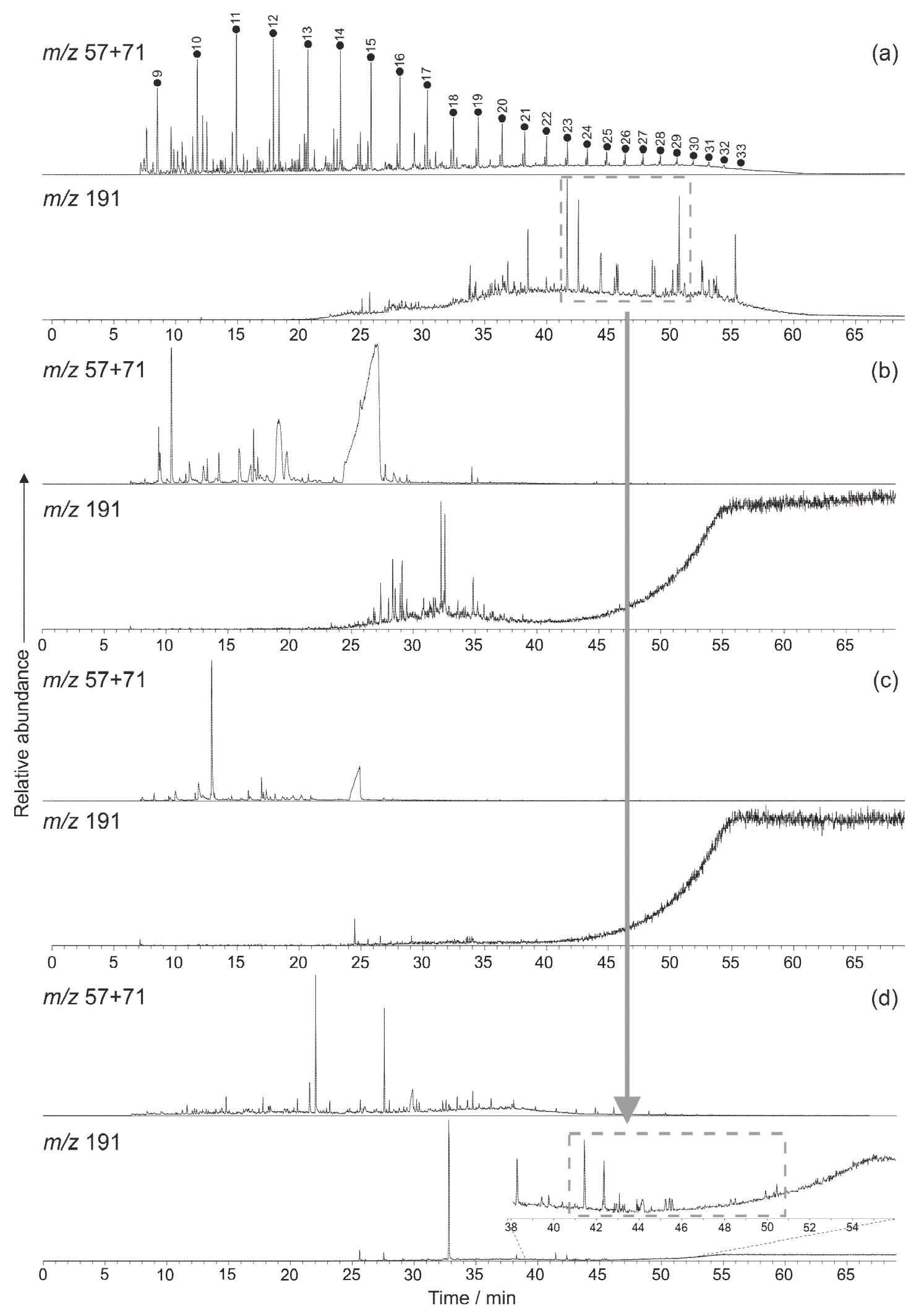

Figure 1. Full m/z 57+71 (alkane) and m/z 191 (hopane) mass chromatograms for the : (a) pitch crust (peaks with filled circles indicate n-alkene/n-alkane doublets, indicative of asphaltenes; accompanying numbers indicate the carbon 
chain lengths of the homologues), (b) the untreated weaving tool, (c) treated weaving tool, and (d) cranium (minor contamination, as shown by the hopane distribution matching that of the pitch crust).

Figure 1a-c depicts py-GC/MS mass chromatograms obtained for the pitch crust and two weaving tool samples. Both $n$-alkene/n-alkane doublets and hopanes, used as proxies for total contamination, were detected in a sample of crust collected from Pitch Lake in 2014, but neither were detected in either the untreated or treated material from the weaving tool, suggesting that the radiocarbon date was reliable.

Material from the small bowl was not analysed using py-GC/MS as pitch was clearly visible in the untreated sample, and there was insufficient material remaining of the pretreated wood.

No distribution of $n$-alkene/ $n$-alkane doublets, indicative of asphaltenes, was observed in untreated bone powder from the cranium. A low intensity distribution of hopanes, paralleling those observed in the pitch tar, was observed, however (Figure 1d). This indicates that sampling had been largely successful in avoiding surface pitch contamination, but confirmed that some pitch was present prior to pretreatment.

\subsection{Optical microscopy}

Pretreated material from both the weaving tool and the small bowl were studied using optical microscopy to look for visual indications of residual pitch. No pitch was observed within the pretreated material from the weaving tool (figure 2A, B), but pitch was clearly still present in the treated wood from the small bowl (figure 2C, D). The weaving tool, while black in colour, had not appeared to be heavily contaminated with pitch when sampling, unlike the small bowl that did clearly contain large quantities of pitch across the surface of the bowl, as well as retaining some within its cavity. 


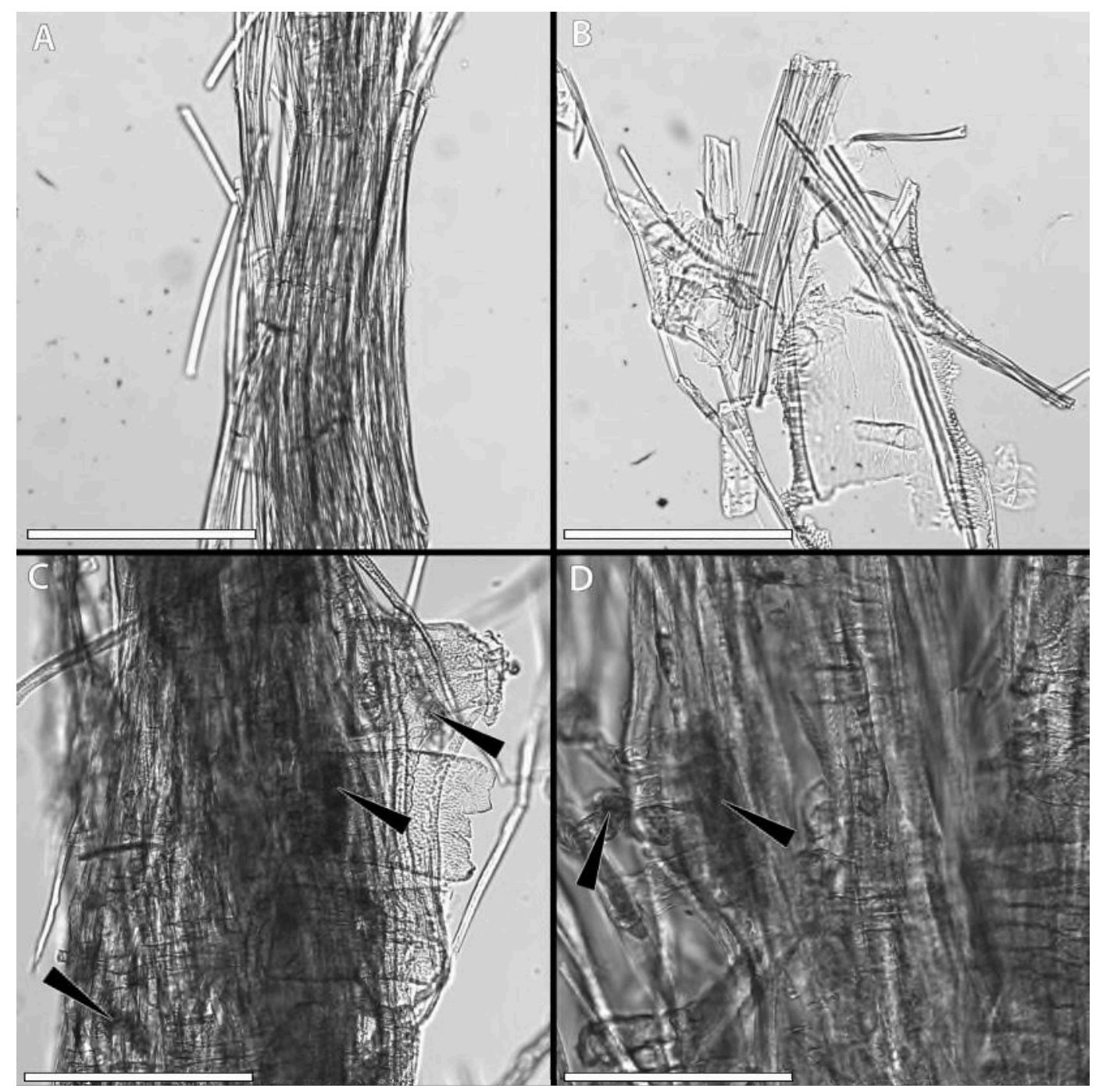

Figure 2A, B: Weaving tool. In A, a group of fibers show hyaline cell walls and no cell contents. In B, the cell walls are similarly hyaline in fibers, parenchyma cells, and a partial vessel element.? Figure 2C, D: Small bowl. Arrowheads show tar inclusions in cells. Partial vessel elements and individual fiber cell walls are hyaline but fiber groups and parenchyma cells show a general pigmentation and areas of tar retention. D shows a higher-magnification image with individual cells showing pigmented contents. Scale bars: $A-C=200 \mu \mathrm{m}, \mathrm{D}=100 \mu \mathrm{m}$.

The microscopy analysis supports the findings of the py-GC/MS, indicating that after pretreatment the sample from the weaving tool was not contaminated with pitch and that the radiocarbon date is reliable. However, the small bowl was still contaminated, and the date is therefore likely to be too old and can only be considered a terminus post quem. It is extremely difficult to estimate the extent of the pitch contamination within the small bowl from the microscopy alone, although we cautiously estimate it is no more than $10 \%$, and maybe as low as 1 - 
$5 \%$. A similar date to that given for the bowl could be produced from a sample with a date of $\sim 3400 \mathrm{BP}$ and just $10 \%$ pitch contamination; a date of $\sim 3700 \mathrm{BP}$ would yield a similar date with $5 \%$ residual pitch.

4. Comparison of radiocarbon dating wood and bone from Rancho La Brea, California, and Pitch Lake, Trinidad.

The results from this study highlight the potential differences in chemical structure and behaviour of the asphalt at the Rancho La Brea tar pits in California and Pitch Lake in Trinidad.

The artefacts from Pitch Lake do, however, seem remarkably clean of pitch in general, compared to the descriptions of material from Rancho La Brea, where samples are described as heavily impregnated with pitch. The reason for the difference in pitch penetration between the two sites is unclear. It may be related to differences in chemical composition of the pitch, and may also reflect the fact that many of the Rancho La Brea specimens were submerged for many thousands of years longer than those in Pitch Lake. A co-author of this communication (ACW) has studied plant material from both sites, and noted that the botanical specimens from Rancho La Brea were often much smaller than the Pitch Lake artefacts, and so may have been fully impregnated far more readily, especially over the extended period submerged in pitch.

The general lack of surface pitch on many (but not all) of the Pitch Lake pieces may also be influenced by unrecorded cleaning of the artefacts when they first emerged from the lake. Verbal reports from locals living close to Pitch Lake suggest that at least some of the artefacts dredged from the lake may have been cleaned in kerosene to remove pitch, but there are no further details or written records to support this.

\section{$\underline{4 . \text { Conclusions }}$}

As the wooden artefacts and human skeletal remains from Pitch Lake had been submerged in pitch for hundreds of years, it was vital to demonstrate the absence of pitch in the material for dating after pretreatment, especially where dates were earlier than anticipated based on current understanding of the archaeology of Trinidad. 
A solvent extraction sequence comprising toluene and methanol similar to that applied to dating fossil material from the Rancho La Brea tar pits in California (Fuller et al., 2014) was identified as the most effective method of removing pitch contamination from wooden artefacts and human skeletal remains from Pitch Lake. Remaining insoluble residue was clearly visible in any pretreated wood or collagen and could easily be removed manually prior to combustion and dating.

Radiocarbon dates for several artefacts were earlier than had been anticipated, potentially indicating the potential presence of residual pitch after pretreatment. As well as routine laboratory quality assurance criteria, more rigorous techniques were required to identify the presence of residual pitch, in particular for wooden artefacts due to the plant origins of much of the pitch. PyGC/MS and optical microscopy were therefore applied to untreated and pretreated material where suitable and when sufficient material was available.

Py-GC/MS demonstrated that bone powder from the human cranium had successfully been sampled away from regions of pitch contamination with only trace amounts of pitch-derived chemical markers remaining. The $\mathrm{C}: \mathrm{N}$ ratio and $\% \mathrm{C}$ content of the collagen were both within expected ranges and did not suggest the presence of an additional source of carbon. The pale golden colour of the collagen further supported this, and overall we conclude that the date of $2222 \pm$ $27 \mathrm{BP}$ is accurate.

Two identical dates of $4472 \pm 32 \mathrm{BP}$ were produced from the same sample of pretreated material from the weaving tool. Not only was this the earliest date from this corpus, it is also earlier than cotton cultivation was expected to have started in Trinidad (Boomert, pers com., 2016). The pretreated wood was pale yellow in colour as expected, and gave no visual indication of residual pitch other than several small specks of insoluble pitch which were easily removed manually prior to dating. Py-GC/MS did not detect the typical asphaltene ( $n$-alkene/ $n$ alkane doublets) and hopane signatures characteristic of pitch in either untreated or pretreated material from the artefact, indicating that sampling had occurred sufficiently far away from any pitch. This is further supported by optical microscopy analysis of the pretreated material that did not find any erroneous contaminants (see also Ostapkowicz et al., submitted). 
The small bowl, which was clearly contaminated with pitch, gave a date of $4106 \pm 30$ BP. Microscopy demonstrated the presence of residual pitch, and hence in this case we conclude that the pretreatment protocol was not rigorous enough and the date can be treated only as a terminus post quem.

This study demonstrates the importance of using varied and relevant techniques to assess the presence of remaining contamination when dating difficult samples. In the case of artefacts from Pitch Lake, it appears that the chemical pretreatments applied here are suitable for some samples but were not rigorous enough for the more-heavily contaminated small bowl.

\section{Acknowledgements:}

The 'Black Pitch, Carved Histories' project was funded by AHRC grant AH/L00268X/1, while Brock was employed at the Oxford Radiocarbon Accelerator Unit, University of Oxford. The authors wish to thank the following institutions: The National Museum and Art Gallery of Trinidad \& Tobago, particularly Lorraine Johnson for supporting work relating to the human cranium and the small bowl; Molly Gaskin (Pointe-a-Pierre Wildfowl Trust, Trinidad), Chris Harris and the late Peter O’Brien Harris, for permissions to sample the weaving tool. We also thank Marlon Green of the National Trust of Trinidad and Tobago and Jalaludin Khan, heritage conservation consultant, for their support of the project. Arie Boomert provided the sample of pitch crust. Ben Fuller and John Southon are thanked for helpful discussions on removal of tar from Rancho La Brea specimens. The authors thank the Natural Environment Research Council, UK, for partial funding of the mass spectrometry facilities at Bristol (Contract No. R8/H10/63; http://www. lmsf.co.uk).

\section{References:}

Ambrose SH. 1990. Preparation and characterization of bone and tooth collagen for isotopic analysis. Journal of Archaeological Science 17(4): 431-451.

Atwooll, AW. Broome DC. 1954. Trinidad Lake Asphalt, 2nd revised edition. The Baynard Press, London

Aufderheide AC, Nissenbaum A, Cartmell L. 2014. Radiocarbon date recovery from bitumen-containing Egyptian embalming resins. JSSEA 31: 87-96. 
Boomert, A. 1984. The Pith Lake in History, Naturalist 5(11):21-27.

Bommert, A, Harris, P. O’B. 1984. The Pitch Lake in Archaeology, Naturalist 5(11):34-45.

Brock F, Bronk Ramsey C, Higham T. 2007. Quality assurance of ultrafiltered bone dating. Radiocarbon 49(2): 187-192.

Brock F, Higham T, Ditchfield P, Bronk Ramsey C. 2010. Current pretreatment methods for AMS radiocarbon dating at the Oxford Radiocarbon Accelerator Unit (ORAU). Radiocarbon 52(1): 103-112..

Coltrain JB, Harris JM, Cerling TE, Ehleringer JR, Dearing M-D, Ward J, Allen J. 2004. Rancho La Brea stable isotope biogeochemistry and its implications for the palaeoecology of late Pleistocene, coastal southern California. Palaeogeography, Palaeoclimatology, Palaeoecology 205: 199-219.

Dee MW, Brock F, Bowles AD, Bronk Ramsey C. 2011. Using a silica substrate to monitor the effectiveness of radiocarbon pretreatment. Radiocarbon 53(4): 705-711.

Flournoy DS, Kirk TK, Highley TL. 1991. Wood decay by brown-rot fungi: Changes in pore structure and cell wall volume. Holzforshung 45(5): 383-388.

Friscia AR, Van Valkenburgh B, Spencer L, Harris J. 2008. Chronology and spatial distribution of large mammal bones in pit 91, Rancho la Brea. Palaios 23(1/2): 35-42.

Fuller BT, Fahrni SM, Harris JM, Aisling BF, Coltrain JB, Gerhart LM, Ward JK, Taylor RE, Southon JR. 2014. Ultrafiltration for asphalt removal from bone collagen for radiocarbon dating and isotopic analysis of Pleistocene fauna at the tar pits of Rancho La Brea, Los Angeles, California. Quaternary Geochronology 22: 85-98.

Fuller BT, Harris JM, Farrell AB, Takeuchi G, Southon JR. 2015. Sample preparation for radiocarbon dating and isotopic analysis of bone from Rancho La Brea. Science Series, No. 42, pp. 151-167. Natural History Museum of Los Angeles County.

Fuller BT, Southon JR, Fahrni SM, Harris JM, Farrell AB, Takeuchi GT, Nehlich O, Richards MP, Guiry EJ, Taylor RE. 2016. No evidence of domestic dog burial with "La Brea Woman". PaleoAmerica 2: 56-59. 
Ho TY, Marcus LF, Berger R. 1969. Radiocarbon dating of petroleumimpregnated bone from tar pits at Rancho La Brea, California. Science 164(3883): 1051-1052.

Languri GM, van der Horst J, Boon JJ. 2002. Characterisation of a unique 'asphalt' samples from the early $19^{\text {th }}$ century Hafkenscheid painting materials collection by analytical pyrolysis MS and GC/MS. Journal of Analytical and Applied Pyrolysis. 63(1): 171-196.

Longin R. 1971. New method of collagen extraction for radiocarbon dating. Nature 230: 241-242.

Newson, LA. 1976. Aboriginal and Spanish Colonial Trinidad: A Study in Culture Contact, Academic Press, London.

O’Keefe F.R., Fet E.V., Harris J.M. 2009. Compilation, calibration, and synthesis of fauna and floral radiocarbon dates, Rancho La Brea, California. Contributions in Science 518: 1-16.

Ostapkowicz J, Bronk Ramsey C, Brock F, Higham T, Wiedenhoeft AC, Ribechini E, Lucejko JJ, Wilson S. 2012. Chronologies in wood and resin: AMS ${ }^{14} \mathrm{C}$ dating of pre-Hispanic Caribbean wood sculpture. Journal of Archaeological Science 39: 2238-2251.

Ostapkowicz J, Brock F, Weidenhoeft AC, Snoeck C, Pouncett J, BakshComeau Y, Schulting R, Claevs P, Mattielli N, Richards M, Boomert A. Submitted Black pitch, carved histories: Radiocarbon dating, wood species identification and strontium isotope analysis of prehistoric wood carvings from Trinidad's Pitch Lake. Journal of Archaeological Science

Quiles A, Delqué-Količ E, Bellot-Gurlet L, Comby-Zerbino C, Méenager M, Paris C, Souprayen C, Vieillescazes C, Andreu-Lanoë, Madrigal K. 2014. Embalming as a source of contamination for radiocarbon dating of Egyptian Mummies: On a new chemical protocol to extract bitumen. ArchaeoSciences, revue d'archéométrie 38: 135-149.

Staff RA, Reynard L, Brock F, Bronk Ramsey C. 2014. Wood pretreatment protocols and measurement of tree-ring standards at the Oxford Radiocarbon Accelerator Unit (ORAU). Radiocarbon 56(2): 709-715. 
Stafford Jr TW, Hare PE, Currie L, Jull AJT, Donahue DJ. 1991. Accelerator Radiocarbon Dating at the Molecular Level. Journal of Archaeological Science 18: 35-72.

Ward JK, Harris JM, Cerling TE, Wiedenhoeft A, Lott MJ, Dearing M-D, Coltrain JB, Ehleringer JR. 2005. Carbon starvation in glacial trees recovered from the La Brea tar pits, southern California. PNAS 102(3):690-694.

Whitehead, N. 1997. The Discoverie of the Large, Rich and Bewtiful Empyre of Guiana, transcribed, annoted and introduced by Neil L. Whitehead, Manchester University Press, Manchester.

Wiltshire, WW. 2007. The Commercial Development of Trinidad Lake Asphalt, SCRIP-J Printers, Ltd., Laventille. 